\section{(6) OPEN ACCESS}

\title{
Efficacy and safety of open-label etanercept on extended oligoarticular juvenile idiopathic arthritis, enthesitis-related arthritis and psoriatic arthritis: part 1 (week 12) of the CLIPPER study
}

\author{
Gerd Horneff, ${ }^{1}$ Ruben Burgos-Vargas, ${ }^{2}$ Tamas Constantin, ${ }^{3}$ Ivan Foeldvari, ${ }^{4}$ \\ Jelena Vojinovic, ${ }^{5}$ Vyacheslav G Chasnyk, ${ }^{6}$ Joke Dehoorne, ${ }^{7}$ Violeta Panaviene, ${ }^{8}$ \\ Gordana Susic, ${ }^{9}$ Valda Stanevica, ${ }^{10}$ Katarzyna Kobusinska, ${ }^{11}$ Zbigniew Zuber, $^{12}$ \\ Richard Mouy, $^{13}$ Ingrida Rumba-Rozenfelde, ${ }^{14}$ Luciana Breda, $^{15}$ Pavla Dolezalova, ${ }^{16}$ \\ Chantal Job-Deslandre, ${ }^{17}$ Nico Wulffraat, ${ }^{18}$ Daniel Alvarez, ${ }^{19}{ }^{19}$ Chuanbo Zang, ${ }^{19}$ \\ Joseph Wajdula, ${ }^{19}$ Deborah Woodworth, ${ }^{19}$ Bonnie Vlahos, ${ }^{19}$ Alberto Martini, ${ }^{20,21}$ \\ Nicolino Ruperto, ${ }^{20}$ for the Paediatric Rheumatology International Trials Organisation \\ (PRINTO)
}

\begin{abstract}
Handling editor Tore K Kvien
- Additional material is published online only. To view please visit the journal online (http://dx.doi.org/10.1136/ annrheumdis-2012-203046).

For numbered affiliations see end of article.
\end{abstract}

\section{Correspondence to} Dr Nicolino Ruperto, Pediatria II, Reumatologia, Istituto G Gaslini, PRINTO, Via G Gaslini 5, Genova 16147, Italy; nicolaruperto@ospedale-gaslini. ge.it

Accepted 1 April 2013 Published Online First 21 May 2013

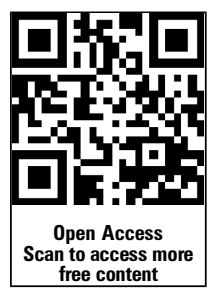

To cite: Horneff $G$, BurgosVargas R, Constantin T, et al. Ann Rheum Dis 2014;73:1114-1122.

\section{ABSTRACT}

Objective To investigate the efficacy and safety of etanercept (ETN) in paediatric subjects with extended oligoarticular juvenile idiopathic arthritis (eoJIA), enthesitisrelated arthritis (ERA), or psoriatic arthritis (PSA).

Methods CLIPPER is an ongoing, Phase $3 \mathrm{~b}$, open-label, multicentre study; the 12-week (Part 1) data are reported here. Subjects with eoJIA (2-17 years), ERA (12-17 years), or PsA (12-17 years) received ETN $0.8 \mathrm{mg} / \mathrm{kg}$ once weekly (maximum $50 \mathrm{mg}$ ). Primary endpoint was the percentage of subjects achieving JIA American College of Rheumatology (ACR) 30 criteria at week 12; secondary outcomes included JIA ACR 50/70/90 and inactive disease. Results 122/127 (96.1\%) subjects completed the study (mean age 11.7 years). JIA ACR $30(95 \% \mathrm{Cl})$ was achieved by $88.6 \%(81.6 \%$ to $93.6 \%)$ of subjects overall; $89.7 \%$ (78.8\% to $96.1 \%$ ) with eoJIA, $83.3 \%$ (67.2\% to $93.6 \%)$ with ERA and $93.1 \%$ (77.2\% to $99.2 \%)$ with PsA. For eoJIA, ERA, or PSA categories, the ORs of ETN vs the historical placebo data were 26.2, 15.1 and 40.7, respectively. Overall JIA ACR 50, 70, 90 and inactive disease were achieved by $81.1,61.5,29.8$ and $12.1 \%$, respectively. Treatment-emergent adverse events (AEs), infections, and serious AEs, were reported in $45(35.4 \%), 58(45.7 \%)$, and $4(3.1 \%)$, subjects, respectively. Serious AEs were one case each of abdominal pain, bronchopneumonia, gastroenteritis and pyelocystitis. One subject reported herpes zoster and another varicella. No differences in safety were observed across the JIA categories.

Conclusions ETN treatment for 12 weeks was effective and well tolerated in paediatric subjects with eoJIA, ERA and PsA, with no unexpected safety findings.

Juvenile idiopathic arthritis (JIA) is the most common childhood chronic rheumatic disease. ${ }^{1-3}$ The term JIA covers seven mutually exclusive categories according to the International League of Associations for Rheumatology (ILAR) classification criteria. $^{4-6}$
Past differences in nomenclature make comparisons between clinical studies difficult, and there is limited evidence-based information for the management of some JIA categories. ${ }^{7}{ }^{8}$ Non-steroidal antiinflammatory drugs (NSAIDs), intra-articular corticosteroids, and disease-modifying antirheumatic drugs (DMARDs; methotrexate (MTX) and sulfasalazine (SSZ)) are the first-line treatments, ${ }^{4} 910$ followed by biologics, such as tumour necrosis factor inhibitors (TNFi) or abatacept in non-responders. ${ }^{11-14}$ The TNFi agent, etanercept (ETN), has shown both shortterm and long-term efficacy and safety in paediatric subjects with polyarticular course JIA. ${ }^{15-19}$ However, the efficacy and safety of ETN in specific ILAR categories, such as extended oligoarticular JIA (eoJIA), enthesitis-related arthritis (ERA) and psoriatic arthritis (PsA) has not been studied thoroughly. ${ }^{20-26}$

The objective of Part I of the CLinical Study In Paediatric Patients of Etanercept for Treatment of ERA, PsA, and Extended Oligoarthritis (CLIPPER) study was to evaluate the efficacy and safety of ETN $0.8 \mathrm{mg} / \mathrm{kg}$ once weekly ( $\max 50 \mathrm{mg} /$ week) in these three categories over the initial 12 -week period.

\section{PATIENTS AND METHODS}

\section{Study design}

The CLIPPER study is Phase 3b, open-label, prospective, multicentre, interventional study divided into two parts: Part I (reported herein) relates to the 12-week primary analyses, while Part II is ongoing and relates to long-term safety and efficacy. Subjects with eoJIA (2-17 years), ERA (12-17 years), or PsA (1217 years) were enrolled and received ETN $0.8 \mathrm{mg} / \mathrm{kg}$ once weekly (maximum dose $50 \mathrm{mg} /$ week). The protocol was reviewed and approved by independent ethics committees/institutional review board at 38 centres in 19 countries included in the Paediatric Rheumatology International Trials Organisation (PRINTO). ${ }^{27}$ All parents/subjects signed and dated an informed consent, and the study was approved by the 
local ethics committee. This study was conducted in compliance with the ethical principles originating in or derived from the Declaration of Helsinki, and in compliance with all International Conference on Harmonisation Good Clinical Practice Guidelines.

\section{Inclusion and exclusion criteria}

Key inclusion criteria: subjects classified as eoJIA, ERA, or PsA ${ }^{5}$; $\geq 2$ active joints (swollen or limitation of motion (LOM) accompanied by either pain or tenderness); history of intolerance or unsatisfactory response to at least a 3-month course of $\geq 1$ DMARD or, only for ERA, unsatisfactory response to at least a 1 -month course of $\geq 1$ NSAID; only one DMARD (MTX, SSZ, chloroquine or hydroxychloroquine), one oral corticosteroid $\leq 0.2 \mathrm{mg} / \mathrm{kg} / \mathrm{day}$ or $10 \mathrm{mg} /$ day (whichever was less), and one NSAID were allowed with no dose changes throughout the study.

Key exclusion criteria: other rheumatic diseases; pustular, or erythrodermic psoriasis; active or history of tuberculosis or evidence of latent tuberculosis, active uveitis within 6 months of baseline, any live (attenuated) vaccine within 2 months of baseline, any medically important infection within 1 month of baseline, or any prior receipt of biologics. The following JIA medications were prohibited during specified washout periods based on the half-life of the product: immunosuppressive drugs (other than glucocorticosteroids or allowed medication) or leflunomide within 6 months, investigational non-biologic drugs within 3 months, non-biologic DMARDs (other than MTX, SSZ, hydroxychloroquine, or chloroquine), combinations of non-biologic DMARDs, ultraviolet $\mathrm{A} / \mathrm{B}$, or psoralen plus UVA within 4 weeks.

\section{Assessments}

The primary endpoint was the percentage of subjects achieving JIA American College of Rheumatology (ACR) 30 criteria $^{28}$ at week 12. Since this was a single-arm open-label study, the primary results were compared with two historical placebo groups from (1) a meta-analysis of JIA studies ${ }^{29}$ and (2) a 12-week randomised, double-blind, placebo-controlled juvenile-onset spondyloarthropathy study (ERA subjects only). ${ }^{30}$ In addition, we compared our results with a historical active control group from a 12-week open-label period of an ETN study of subjects with polyarticular juvenile rheumatoid arthritis (JRA). ${ }^{17}$ Secondary endpoints included the percentage of subjects achieving JIA ACR 30 at all time points other than week 12, JIA ACR 50, 70, 90, inactive disease status with physician global assessment (PGA) of disease activity set to zero (minimal value on the scale corresponding to no disease activity), ${ }^{31}$ and the changes from baseline to week 12 for each of the JIA ACR core components ${ }^{28}$ : PGA of disease activity visual analogue scale (VAS; 0-10 on a 21-circle VAS); parent's global assessment of the child's overall well being VAS (0-10 on a 21-circle VAS); number of active joints (0-73); number of joints with LOM (0-69); CRP levels in mg/l; cross-culturally adapted Childhood Health Assessment Questionnaire (CHAQ) score, completed by parent. ${ }^{32-34}$ Additional endpoints included parent's assessment of the child's pain (0-10 VAS) and duration of morning stiffness in minutes, completed by parents. Subjects with ERA were also assessed with the tender entheseal assessment (0-66); overall back pain and nocturnal back pain (0-100 mm VAS), completed by parents ${ }^{35}$; modified Schober's test ${ }^{36}$ in centimetres $(\mathrm{cm})$. Subjects with PsA were also assessed for the extent of psoriasis with the psoriasis body surface area (BSA) and PGA of psoriasis $(0-5)$.

\section{Safety}

Compliance was measured at the site by using vial counts, diary cards and information provided by the parent and/or subject; subjects were considered compliant if they received $\geq 80 \%$ of planned ETN doses. Adverse events (AEs), including infections, injection site reactions (ISRs), serious AEs (SAEs), including serious infections, laboratory analyses and vital signs measurements were recorded throughout the study (MedDRA V.14.0 dictionary). To assess immunogenicity, serum samples at baseline, week 12 , or upon early withdrawal, were analysed for the presence of ETN antibodies and neutralising antibodies.

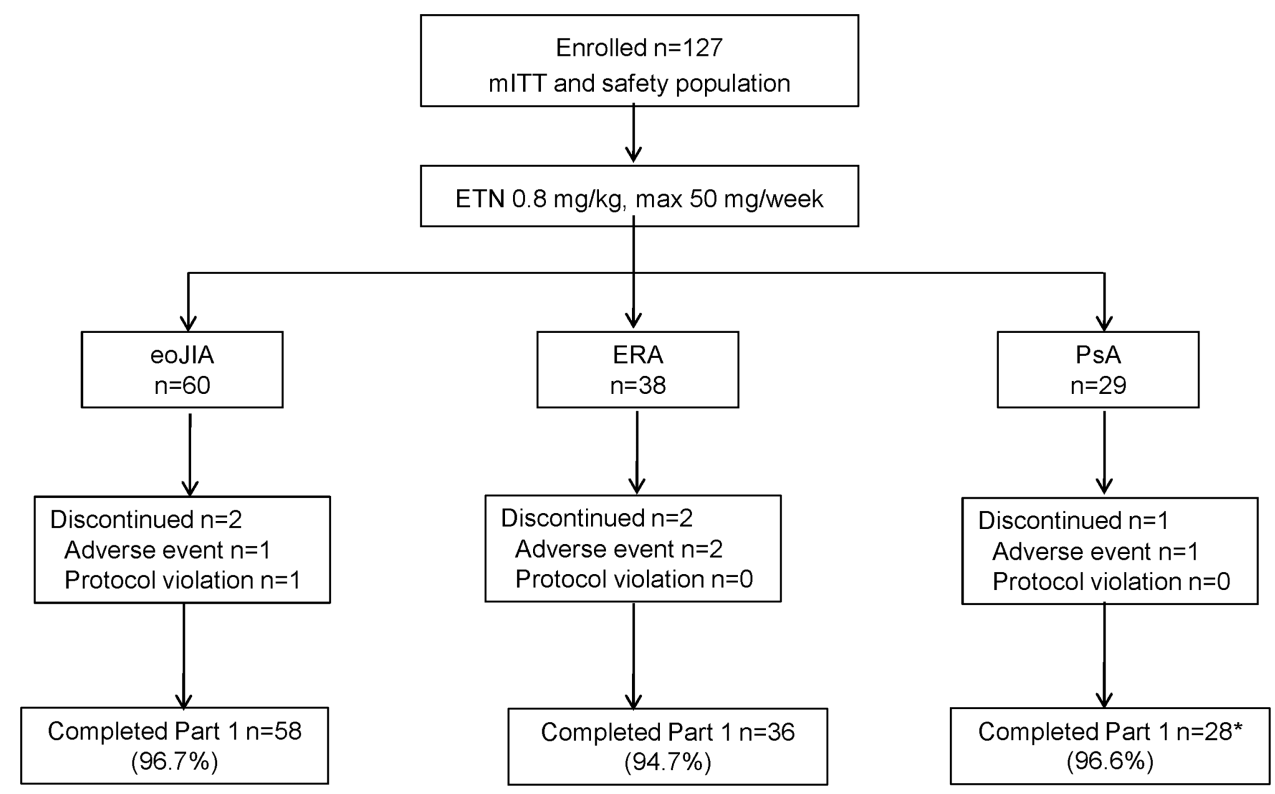

Figure 1 Subject disposition. Adverse events include infections. All subjects who discontinued ETN continued to be monitored for safety. * One PsA subject withdrew early but had assessment data for Week 12; therefore, analyses were performed on $n=29$ subjects. 


\section{Statistical methods}

The sample size was determined by the 100 subjects anticipated to be enrolled in the study. It was expected that the half-width of the $95 \%$ CI would be no more than $10 \%$ for estimation of the JIA ACR 30 response rate. All efficacy analyses were based on the modified intent-to-treat (mITT) population defined as all subjects who received $\geq 1$ dose of ETN. For the overall population, and for each of the JIA categories, the analysis was based on the observed cases (OC) data. Descriptive summary statistics for observed data were provided. Logistic regression analysis was used to compare the JIA ACR 30 data with historical placebo data and historical active control data: ORs and corresponding 95\% CI were computed for the overall population and for each of the JIA categories. Safety analyses were based on the mITT population.

\section{RESULTS}

\section{Subjects}

A total of 127 subjects (eoJIA $n=60$, ERA $n=38$ and PsA $\mathrm{n}=29$ ) were enrolled (figure 1) with 122 (96.1\%) completing week 12. Mean age, weight, height and body mass index (BMI) were lower in the eoJIA subgroup than the ERA and PsA subgroups as per inclusion criteria (table 1). ERA subjects were predominantly male $(30,78.9 \%)$. Of the 29 subjects with PsA, 21 had psoriatic lesions (19 plaque psoriasis and 2 guttate psoriasis). Concomitant DMARDs were received by $85.8 \%$ of subjects overall, with MTX most commonly used. SSZ and glucocorticoids were more frequently used in ERA subjects. All 127 subjects were $\geq 80 \%$ compliant with ETN and 115 (90.6\%) were $100 \%$ compliant.

Table 1 Demographic and disease characteristics at baseline

\begin{tabular}{|c|c|c|c|c|}
\hline & $\begin{array}{l}\text { eoJIA } \\
n=60\end{array}$ & $\begin{array}{l}\text { ERA } \\
\mathrm{n}=38\end{array}$ & $\begin{array}{l}\text { PsA } \\
n=29\end{array}$ & $\begin{array}{l}\text { Overall } \\
n=127\end{array}$ \\
\hline Age at baseline, years & $8.6(4.6)$ & $14.5(1.6)$ & $14.5(2.0)$ & $11.7(4.5)$ \\
\hline $2-4$ years $n(\%)$ & $15(25.0)$ & - & - & $15(11.8)$ \\
\hline $5-11$ years $n(\%)$ & $23(38.3)$ & - & - & $23(18.1)$ \\
\hline $12-17$ years $n(\%)$ & $22(36.7)$ & $38(100.0)$ & $29(100.0)$ & $89(70.1)$ \\
\hline Female, $\mathrm{n}(\%)$ & $41(68.3)$ & $8(21.1)$ & $23(79.3)$ & $72(56.7)$ \\
\hline Weight, kg & $34.8(18.9)$ & $54.4(8.8)$ & $60.0(14.2)$ & $46.4(19.0)$ \\
\hline $\mathrm{BMI}, \mathrm{kg} / \mathrm{m}^{2}$ & $17.9(3.6)$ & $19.5(2.4)$ & $22.7(4.5)$ & $19.5(4.0)$ \\
\hline Age at onset & $6.1(4.5)$ & $12.5(2.1)$ & $12.6(2.7)$ & $9.5(4.8)$ \\
\hline Disease duration, months & $31.6(31.7)$ & $23.0(19.8)$ & $21.8(20.2)$ & $26.8(26.4)$ \\
\hline HLA-B27 presence, n (\%) & $9(15.0)$ & $26(68.4)$ & $3(10.3)$ & $38(29.9)$ \\
\hline \multicolumn{5}{|l|}{ Disease characteristics } \\
\hline PGA of disease activity VAS & $5.0(1.8)$ & $5.4(1.9)$ & $4.7(1.4)$ & $5.0(1.8)$ \\
\hline Parent global assessment of child's overall well-being VAS & $4.8(2.4)$ & $5.4(2.3)$ & $4.6(2.2)$ & $5.0(2.3)$ \\
\hline No. of active joints & $7.6(5.1)$ & $5.2(3.6)$ & $7.0(4.3)$ & $6.7(4.6)$ \\
\hline No. of joints with LOM & $6.3(4.4)$ & $4.8(4.0)$ & $5.6(4.1)$ & $5.7(4.2)$ \\
\hline No. of painful joints & $5.5(4.1)$ & $6.7(4.9)$ & $7.8(7.0)$ & $6.4(5.2)$ \\
\hline No. of swollen joints & $6.5(4.8)$ & $3.8(2.8)$ & $5.6(3.7)$ & $5.5(4.2)$ \\
\hline $\mathrm{CRP}, \mathrm{mg} / \mathrm{I}^{*}$ & $6.3(10.6)$ & $15.3(21.5)$ & $3.2(4.7)$ & $8.2(14.7)$ \\
\hline CHAQ score & $0.9(0.7)$ & $0.7(0.5)$ & $0.7(0.6)$ & $0.8(0.6)$ \\
\hline Parent global assessment of child's pain VAS & $4.8(2.6)$ & $5.8(2.5)$ & $4.6(2.3)$ & $5.1(2.5)$ \\
\hline Morning stiffness, minutes & $72.8(97.2)$ & $89.3(128.9)$ & $54.3(54.2)$ & $73.5(100.6)$ \\
\hline \multicolumn{5}{|l|}{ JIA category-specific characteristics } \\
\hline Tender entheseal score & - & $5.9(9.4)$ & - & - \\
\hline Overall back pain VAS, mm & - & $25.9(28.0)$ & - & - \\
\hline Nocturnal back pain VAS, mm & - & $16.4(27.8)$ & - & - \\
\hline Modified Schober's test, $\mathrm{cm}$ & - & $15.0(1.9)$ & - & - \\
\hline Psoriasis BSA, \% & - & - & $10.4(13.4)$ & - \\
\hline PGA of psoriasis & - & - & $1.8(1.4)$ & \\
\hline \multicolumn{5}{|l|}{ Concomitant therapy, no. of subjects (\%)† } \\
\hline Any DMARD & $54(90.0)$ & $32(84.2)$ & $23(79.3)$ & $109(85.8)$ \\
\hline Methotrexate & $49(81.7)$ & $18(47.4)$ & $19(65.5)$ & $86(67.7)$ \\
\hline Sulfasalazine & $3(5.0)$ & $12(31.6)$ & $4(13.8)$ & $19(15.0)$ \\
\hline Chloroquine & $1(1.7)$ & 0 & 0 & $1(0.8)$ \\
\hline Hydroxychloroquine & $1(1.7)$ & $2(5.3)$ & 0 & $3(2.4)$ \\
\hline Oral corticosteroid & 7 (11.7) & $8(21.1)$ & $1(3.5)$ & $16(12.6)$ \\
\hline Oral NSAID & $32(53.3)$ & $26(68.4)$ & $16(55.2)$ & $74(58.3)$ \\
\hline
\end{tabular}

All values are mean (SD), unless otherwise specified.

*Normal ranges for CRP values were as follows: $0-3$ years, female $<7.9 \mathrm{mg} / \mathrm{l}$, male $<11.2 \mathrm{mg} / \mathrm{l} ; 4-10$ years, female $<10.0 \mathrm{mg} / \mathrm{l}$, male $<7.0 \mathrm{mg} / \mathrm{l} ; 11-14$ years, female $<8.1 \mathrm{mg} / \mathrm{l}$, male $<7.6 \mathrm{mg} / \mathrm{l} ; 15-17$ years, female $<7.9 \mathrm{mg} / \mathrm{l}$, male $<7.9 \mathrm{mg} / \mathrm{l} ; 18-120$ years, female $<5.0 \mathrm{mg} / \mathrm{ll}$, male $<5.0 \mathrm{mg} / \mathrm{l}$.

tNumber of patients within concomitant therapy groups differ from baseline only for oral NSAIDs where two subjects in each treatment group added an oral NSAID post baseline.

BSA, body surface area; CHAQ, Childhood Health Assessment Questionnaire; CRP, C-Reactive Protein; DMARD, disease-modifying anti-rheumatic drug; eoJIA, extended oligoarticular Juvenile idiopathic arthritis; ERA, enthesitis-related arthritis; LOM, limitation of motion; NSAID, Non-steroidal anti-inflammatory drug; PGA, physician global assessment; VAS, Visual Analogue Scale. 


\section{Efficacy}

At week 12, overall $88.6 \%$ (95\% CI $81.6 \%$ to 93.6\%) of subjects achieved JIA ACR 30 (figure 2A). JIA ACR 30 (95\% CI) was achieved by $89.7 \%(78.8 \%$ to $96.1 \%)$ of subjects with eoJIA, $83.3 \%$ (67.2\% to 93.6\%) with ERA and $93.1 \%(77.2 \%$ to $99.2 \%$ ) with PsA. In comparison of the JIA ACR 30 result overall with historical data from a meta-analysis of JIA studies, ${ }^{29}$ the ORs (95\% CI) showed a significant advantage of ETN over placebo (OR 23.5; 12.5 to 44.3; figure 2B). For eoJIA, ERA, and PsA categories, the ORs $(95 \% \mathrm{CI})$ of ETN versus the historical placebo data ${ }^{29}$ were 26.2 (10.6 to 64.2$), 15.1$ (6.0 to 38.2 ) and 40.7 (9.4 to 176.9), respectively. Compared with data from subjects from a jo-SpA study, ${ }^{30}$ in subjects with ERA, OR showed ETN to be significantly more effective than placebo
(OR 6.7, 95\% CI 1.7 to 26.3). The JIA ACR 30 response rate in this study was comparable with the historical active control data $^{17}$ overall (OR $2.0 ; 0.5$ to 8.3 ) and for the three JIA categories, eoJIA (OR 2.0; 0.4 to 9.8), ERA (OR $1.5 ; 0.2$ to 10.4) and PsA (OR 2.3; 0.2 to 21.3) (figure 2C). At week 12 (figure $3 \mathrm{~A})$ overall, JIA ACR 50, 70 and 90 responses (95\% CI) were achieved by $81.1 \%(73.1 \%$ to $87.7 \%), 61.5 \%(52.2 \%$ to $70.1 \%)$ and $29.8 \%(21.8 \%$ to $38.7 \%)$ of subjects, respectively. In subjects with eoJIA, the JIA ACR 50/70/90 response rates were generally similar across the three age groups (figure $3 \mathrm{~B}$ ). In total, inactive disease $(95 \% \mathrm{CI})$ was achieved by $12.1 \%(6.9 \%$ to $19.2 \%)$ by week $12 ; 11.9 \%$ (4.9\% to $22.9 \%), 16.7 \%(6.4 \%$ to $32.8 \%)$ and $6.9 \%(0.8 \%$ to $22.8 \%)$ in subjects with eoJIA, ERA and PsA, respectively.
Figure 2 Juvenile idiopathic arthritis (JIA) American College of Rheumatology (ACR) response 30, 50, 70,90 and inactive disease status. (A) JIA ACR 30 response rates by JIA category over 12 weeks. Data are compared with historical placebo data $^{29,30}$ and historical active control. ${ }^{17}$ * JIA ACR 30 historical placebo rate $=28.9 \%(95 \% \mathrm{Cl} 24.0$ to 34.2; $n=323) .{ }^{29}{ }^{\dagger} \mathrm{JAA}$ ACR 30 historical placebo rate $=42.8 \%(95 \% \mathrm{Cl} 16.9$ to 68.8; $n=14) .{ }^{30} \neq$ JIA ACR 30 historical active-control response rate at Week $12=73.9 \%(95 \% \mathrm{Cl} 63.6$ to 84.3 ; $\mathrm{n}=69) .{ }^{17}$ (B) OR (95\% Cl) of JIA ACR 30 response rates at week 12 vs historical placebo data. Observed cases, mITT population. Log scale used for horizontal axis. *JIA ACR 30 historical placebo rate $=28.9 \%(95 \%$ Cl 24.0, 34.2; $n=323) .{ }^{29}$ Six historical studies treated individually in the logistic regression model (adjusted). ** JIA ACR 30 historical placebo rate $=$ $42.8 \%(95 \% \mathrm{Cl} 16.9,68.8 ; n=14) .{ }^{30}$ (C) OR (95\% CI) of JIA ACR 30 response rates at week 12 vs historical active control. Observed cases, mITT population. Log scale used for horizontal axis. Historical active control data taken from; ${ }^{17}$ JIA ACR 30 response rate at Week $12=73.9 \%$ (95\% Cl 63.6 to 84.3; $n=69)$.

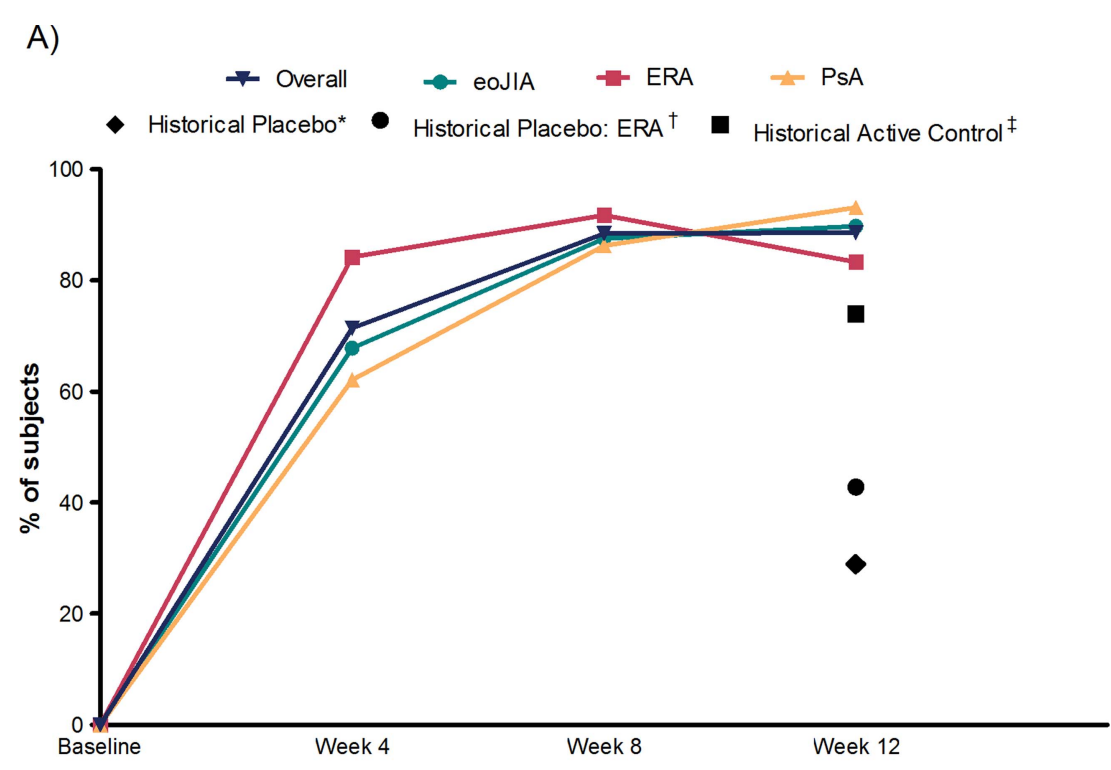

B)

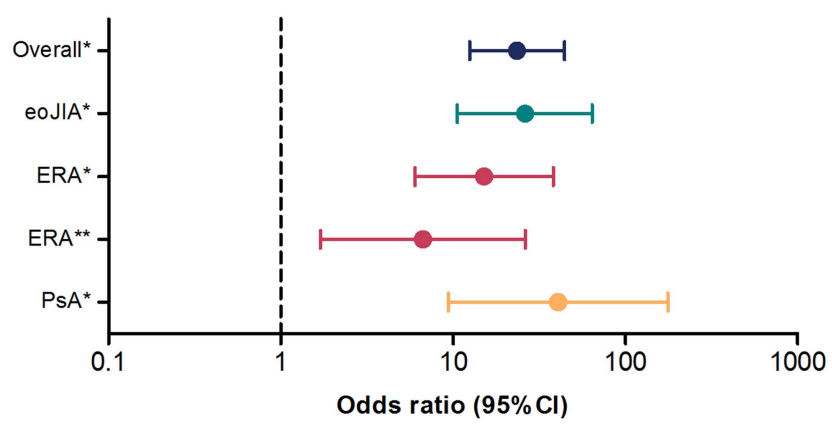

C)

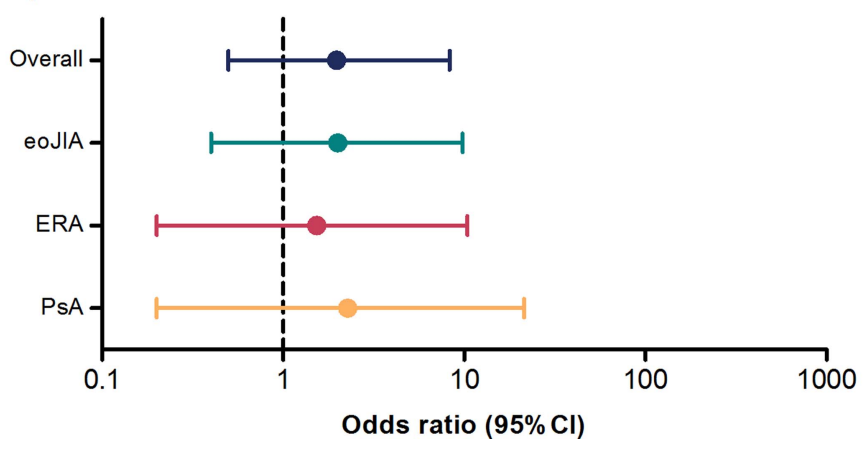


Figure 3 Juvenile idiopathic arthritis (JIA) American College of Rheumatology (ACR) 50, 70, 90 responses and inactive disease at week 12. (A) JIA ACR 50, 70, 90 responses and inactive disease status (secondary outcomes) according to JIA category at week 12. (B) JIA ACR 30, 50, 70,90 responses and inactive disease according to age groups in eoJIA at week 12. Observed cases, mITT population. Error bars represent $95 \% \mathrm{Cl}$.

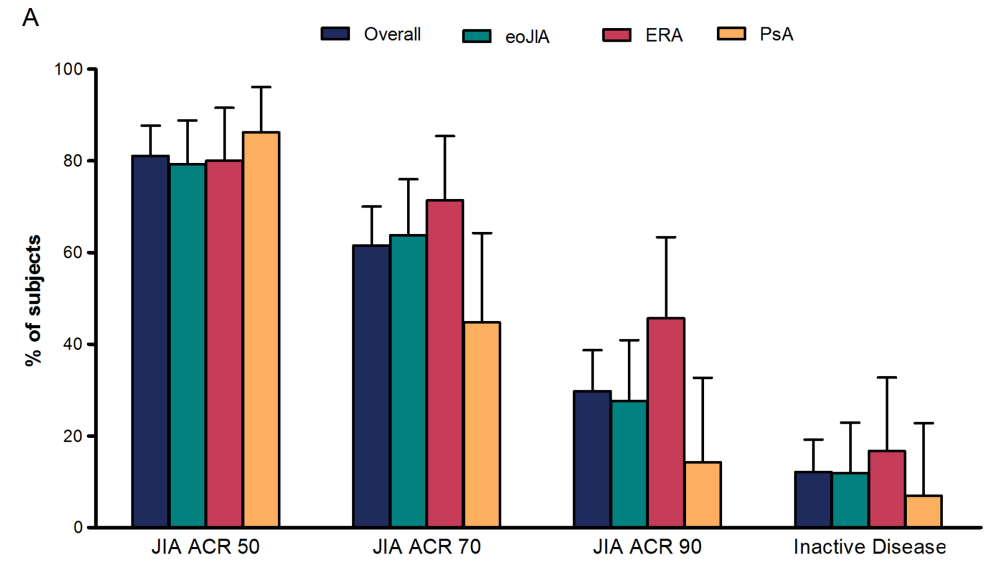

.

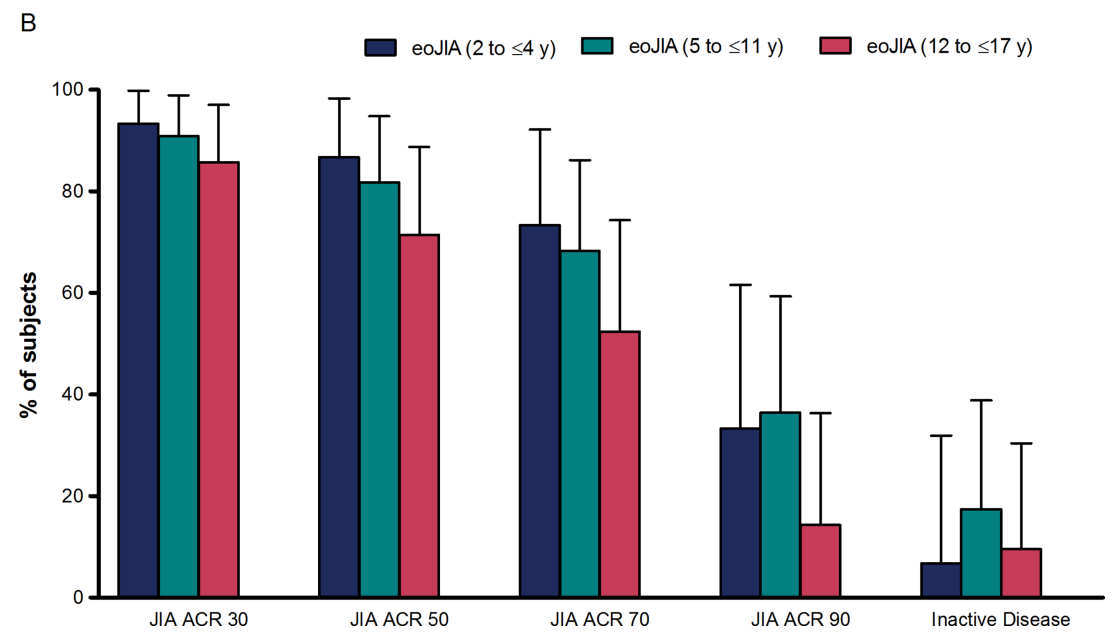

Overall, improvements greater than 50\% from baseline at week 12 were observed for each of the JIA ACR core components (table 2 ).

In subjects with ERA, improvement greater than 50\% from baseline was observed for the tender entheseal score. For subjects with PsA, 48.2\% improvement in BSA of psoriasis and $39.6 \%$ improvement in PGA of psoriasis was observed.

\section{Safety}

Mean duration of ETN exposure was 12.6 (SD 1.6) weeks (29.2 subject-years). Mean weekly ETN dose was 35.0 (SD 13.1) mg.

Non-infectious treatment-emergent AEs (TEAEs; table 3) occurred in $45(35.4 \%)$ subjects leading to discontinuation in two subjects: one for asthenia and pyrexia (considered severe and unrelated to ETN) and the other for fatigue, dizziness and wheezing (considered moderate and related to ETN); both resolved without sequelae. Overall, the most commonly reported non-infectious TEAEs were headache, abdominal pain, diarrhoea, fatigue and pyrexia. No differences in the rates of non-infectious TEAEs were observed among the three categories. For subjects with eoJIA, five (33.3\%), 10 (43.5\%) and six $(27.3 \%)$ subjects reported non-infectious TEAEs in the 2-4 years, 5-11 years and 12-17 years age groups, respectively. No clinically meaningful differences in non-infectious TEAEs were observed across these three age groups.

Treatment-emergent infections were reported in $58(45.7 \%)$ subjects mainly upper respiratory tract infection, pharyngitis and rhinitis. Two (1.6\%) subjects withdrew from ETN treatment due to treatment-emergent serious infections: one case each of bronchopneumonia and pyelocystitis. Both cases led to hospitalisation and were considered mild and unrelated to ETN and resolved without sequelae. No differences in the rates of treatment-emergent infections were observed among the three categories. Treatment-emergent infections by age group in the eoJIA subjects were 11 (73.3\%), 12 (52.2\%) and 8 (36.4\%) for 2-4 years, 5-11 years and 12-17 years, respectively. One mild case of an uncomplicated scarlet fever occurred in a 4-year-old male and resolved in 11 days with anti-infective agent treatment.

For non-infectious SAEs, there was one case $(0.8 \%)$ of abdominal pain which led to hospitalisation, resolved without sequelae, and considered moderate and unrelated to ETN.

Serious treatment-emergent infections considered medically important were reported in three $(2.4 \%)$ subjects: one case each of gastroenteritis and the cases of bronchopneumonia and pyelocystitis mentioned previously, all resolved within a week. Two $(1.6 \%)$ cases of infections considered preventable by vaccination were reported in subjects not previously vaccinated: one case of varicella and one case of herpes zoster occurring in two dermatomes. No cases of malignancy, autoimmune disorders, demyelinating disorders, infections considered preventable by vaccination in subjects previously vaccinated, or deaths were reported.

Five $(4.0 \%)$ subjects had Grade 3 laboratory test results: three $(2.4 \%)$ with decreased neutrophil values, one $(0.8 \%)$ with increased total bilirubin values and one $(0.8 \%)$ with increased alkaline phosphatase values. Overall, 10 subjects had increased aminotransferase (AT) values, with eight subjects reporting peak 
Table 2 Changes from baseline in effectiveness measures at week 12

\begin{tabular}{|c|c|c|c|c|}
\hline \multirow[b]{2}{*}{ JIA ACR core components } & \multicolumn{4}{|c|}{ Change from baseline at week 12 , mean $(95 \% \mathrm{CI})[\%]$} \\
\hline & $\begin{array}{l}\text { eoJIA } \\
n=58\end{array}$ & $\begin{array}{l}\text { ERA } \\
n=36\end{array}$ & $\begin{array}{l}\text { PsA } \\
n=29\end{array}$ & $\begin{array}{l}\text { Overall } \\
n=123\end{array}$ \\
\hline PGA of disease activity & $\begin{array}{l}-3.5(-3.9 \text { to }-3.1) \\
{[-73.2 \%]}\end{array}$ & $\begin{array}{l}-3.9(-4.6 \text { to }-3.3) \\
{[-70.9 \%]}\end{array}$ & $\begin{array}{l}-3.0(-3.5 \text { to }-2.5) \\
{[-65.0 \%]}\end{array}$ & $\begin{array}{l}-3.5(-3.8 \text { to }-3.2) \\
{[-70.6 \%]}\end{array}$ \\
\hline Parent global assessment of child's overall well being & $\begin{array}{l}-2.8(-3.5 \text { to }-2.2) \\
{[-53.1 \%]}\end{array}$ & $\begin{array}{l}-2.8(-3.7 \text { to }-1.9) \\
{[-47.6 \%]}\end{array}$ & $\begin{array}{l}-2.4(-3.1 \text { to }-1.6) \\
{[-47.7 \%]}\end{array}$ & $\begin{array}{l}-2.7(-3.1 \text { to }-2.3) \\
{[-50.2 \%]}\end{array}$ \\
\hline No. of active joints & $\begin{array}{l}-5.5(-6.7 \text { to }-4.2) \\
{[-69.8 \%]}\end{array}$ & $\begin{array}{l}-4.3(-5.4 \text { to }-3.1) \\
{[-77.7 \%]}\end{array}$ & $\begin{array}{l}-5.2(-6.8 \text { to }-3.6) \\
{[-73.8 \%]}\end{array}$ & $\begin{array}{l}-5.1(-5.8 \text { to }-4.3) \\
{[-73.0 \%]}\end{array}$ \\
\hline No. of joints with LOM & $\begin{array}{l}-4.5(-5.6 \text { to }-3.3) \\
{[-64.1 \%]}\end{array}$ & $\begin{array}{l}-3.4(-4.1 \text { to }-2.6) \\
{[-67.4 \%]}\end{array}$ & $\begin{array}{l}-4.3(-5.7 \text { to }-2.9) \\
{[-71.7 \%]}\end{array}$ & $\begin{array}{l}-4.1(-4.8 \text { to }-3.4) \\
{[-66.9 \%]}\end{array}$ \\
\hline $\mathrm{CRP}^{*}, \mathrm{mg} / \mathrm{l}$ & $\begin{array}{l}-2.8(-4.9 \text { to }-0.7) \\
{[-18.9 \%]}\end{array}$ & $\begin{array}{l}-13.2(-20.5 \text { to }-5.8) \\
{[-36.8 \%]}\end{array}$ & $\begin{array}{l}-1.3(-2.8 \text { to }-0.20) \\
{[-11.0 \%]}\end{array}$ & $\begin{array}{l}-5.4(-7.8 \text { to }-2.9) \\
{[-22.1 \%]}\end{array}$ \\
\hline CHAQ & $\begin{array}{l}-0.5(-0.7 \text { to }-0.4) \\
{[-52.2 \%]}\end{array}$ & $\begin{array}{l}-0.5(-0.7 \text { to }-0.3) \\
{[-57.8 \%]}\end{array}$ & $\begin{array}{l}-0.4(-0.6 \text { to }-0.2) \\
{[-51.3 \%]}\end{array}$ & $\begin{array}{l}-0.5(-0.6 \text { to }-0.4) \\
{[-53.6 \%]}\end{array}$ \\
\hline \multicolumn{5}{|l|}{ Other assessments } \\
\hline Parent global assessment of child's pain VAS & $\begin{array}{l}-3.2(-3.8 \text { to }-2.5) \\
{[-58.9 \%]}\end{array}$ & $\begin{array}{l}-3.2(-4.2 \text { to }-2.2) \\
{[-44.9 \%]}\end{array}$ & $\begin{array}{l}-2.6(-3.4 \text { to }-1.8) \\
{[-46.6 \%]}\end{array}$ & $\begin{array}{l}-3.0(-3.5 \text { to }-2.6) \\
{[-51.9 \%]}\end{array}$ \\
\hline Morning stiffness (min) & $\begin{array}{l}-60.3(-83.6 \text { to }-37.0) \\
{[-61.5 \%]}\end{array}$ & $\begin{array}{l}-65.6(-97.6 \text { to }-33.6) \\
{[-64.1 \%]}\end{array}$ & $\begin{array}{l}-47.9(-67.3 \text { to }-28.6) \\
{[-77.2 \%]}\end{array}$ & $\begin{array}{l}-58.9(-73.7 \text { to }-44.1) \\
{[-66.0 \%]}\end{array}$ \\
\hline \multicolumn{5}{|l|}{ JIA category-specific assessments } \\
\hline Tender entheseal score & - & $\begin{array}{l}-4.4(-6.3 \text { to }-2.4) \\
{[-57.8 \%]}\end{array}$ & - & - \\
\hline Back pain VAS & - & $\begin{array}{l}-12.5(-21.3 \text { to }-3.7) \\
{[-21.2 \%]}\end{array}$ & - & - \\
\hline Nocturnal back pain VAS & - & $\begin{array}{l}-8.9(-16.7 \text { to }-1.2) \\
{[-6.8 \%]}\end{array}$ & - & - \\
\hline Modified Schober's test ${ }^{\dagger}$ & - & $\begin{array}{l}0.35^{\ddagger}(-0.02 \text { to } 0.72) \\
{[9.7 \%]}\end{array}$ & - & - \\
\hline BSA, $\%$ & - & - & $\begin{array}{l}-6.7(-10.6 \text { to }-2.9) \\
{[-48.2 \%]}\end{array}$ & - \\
\hline PGA of psoriasis ${ }^{\S}$ & - & - & $\begin{array}{l}-1.0(-1.4 \text { to }-0.6) \\
{[-39.6 \%]}\end{array}$ & - \\
\hline \multicolumn{5}{|c|}{$\begin{array}{l}\text { All values are the mean change from baseline ( } 95 \% \mathrm{Cl} \text { ) ( } \% \text { change from baseline). mITT population (observed cases). } \\
\text { *For CRP: eoJIA } n=58, \text { ERA } n=34, \operatorname{PSA} n=28 \text { and total } n=120 \text {. } \\
\text { tERA } n=35 \text {. } \\
\text { fchange from baseline calculated after subtracting } 10 \text { from the baseline and week } 12 \text { scores. } \\
\S P s A n=28 \text {. } \\
\text { ACR, American College of Rheumatology; BSA, body surface area; CHAQ, Childhood Health Assessment Questionnaire; }\end{array}$} \\
\hline
\end{tabular}

increase of $>2 \times$ to $\leq 3 \times$ upper limit of normal (ULN) AT, and two subjects reporting $>3 \times$ ULN AT values. A total of seven $(5.5 \%)$ subjects tested positive for anti-ETN antibodies, five of these had ERA and two had PsA. None of these subjects tested positive for neutralising antibodies. The presence of ETN antibodies did not have an apparent impact on efficacy or safety.

Vital signs of potential clinical interest were observed in six subjects. Of these, one had a decreased diastolic blood pressure of $40 \mathrm{~mm} \mathrm{Hg}$. The other five cases were of elevated systolic blood pressure ranging from $141 \mathrm{~mm} \mathrm{Hg}$ to $150 \mathrm{~mm} \mathrm{Hg}$ which were Grade 2 in severity.

\section{DISCUSSION}

This open-label study provides evidence that ETN at $0.8 \mathrm{mg} / \mathrm{kg}$ once weekly is both effective and well tolerated in paediatric subjects with eoJIA, ERA, or PsA over 12 weeks of treatment. Beyond the effectiveness of ETN that was reflected in the arthritis-related variables measured in all three categories, there were substantial improvements in the tender entheseal score, back pain and nocturnal back pain in ERA patients, as well as improvements in BSA and PGA of psoriasis in PsA patients.
Until now, information on the safety and efficacy of ETN in paediatric subjects has been obtained largely from polyarticular course JIA. This functional class, defined as having at least five active joints, comprises about one-third of JIA, and includes extended oligoarthritis, and polyarthritis rheumatoid factor positive or negative or systemic arthritis without systemic sign/ symptoms at the time of drug initiation. ${ }^{4}$ Our study was specifically designed with the aim to investigate the effect of ETN treatment on three specific JIA categories: eoJIA, ERA and PsA. Although a limited number of eoJIA patients were included in the publication by Lovell et al ${ }^{12}$ using the previous classification criteria of JRA, further study of this patient population was determined to be of medical interest by the sponsor and the regulatory agency due to the paucity of ETN data in eoJIA patients.

Considering the existing information on the efficacy of ETN in polyarticular course JIA, it was deemed unethical to have a placebo arm in this paediatric study. Therefore, placebo data based on a meta-analysis from previous JIA studies were used as one of the prespecified comparators. The JIA ACR 30 response rates overall and for each category were significantly higher than the placebo historical control. ${ }^{29}$ In addition, a comparison of 
Table 3 Summary of safety findings

\begin{tabular}{|c|c|c|c|c|}
\hline & \multicolumn{4}{|c|}{ No. of subjects $(\%)$} \\
\hline & eoJIA $(n=60)$ & ERA $(n=38)$ & $\operatorname{PsA}(n=29)$ & Overall $(n=127)$ \\
\hline Treatment-emergent AEs* & $21(35.0)$ & $16(42.1)$ & $8(27.6)$ & $45(35.4)$ \\
\hline Treatment-emergent AEs leading to withdrawal ${ }^{*}$ & 0 & $2(5.3)$ & 0 & $2(1.6)$ \\
\hline \multicolumn{5}{|l|}{ Treatment-emergent non-infectious AEs in $\geq 5 \%$ subjects } \\
\hline Headache & $2(3.3)$ & $2(5.3)$ & $3(10.3)$ & $7(5.5)$ \\
\hline Abdominal pain & 0 & $4(10.5)$ & 0 & $4(3.1)$ \\
\hline Diarrhoea & $1(1.7)$ & $3(7.9)$ & 0 & $4(3.1)$ \\
\hline Fatigue & 0 & $4(10.5)$ & 0 & $4(3.1)$ \\
\hline Pyrexia & $3(5.0)$ & $1(2.6)$ & 0 & $4(3.1)$ \\
\hline Aspartate aminotransferase increased & $3(5.0)$ & 0 & 0 & $3(2.4)$ \\
\hline Myalgia & 0 & $3(7.9)$ & 0 & $3(2.4)$ \\
\hline Decreased appetite & 0 & $2(5.3)$ & 0 & $2(1.6)$ \\
\hline Back pain & 0 & 0 & $2(6.9)$ & $2(1.6)$ \\
\hline Epistaxis & 0 & $2(5.3)$ & 0 & $2(1.6)$ \\
\hline Respiratory disorder & 0 & 0 & $2(6.9)$ & $2(1.6)$ \\
\hline Allergic rhinitis & 0 & $2(5.3)$ & 0 & $2(1.6)$ \\
\hline Wheezing & 0 & $2(5.3)$ & 0 & $2(1.6)$ \\
\hline Treatment-emergent ISRs & $4(6.67)$ & $4(10.53)$ & $2(6.90)$ & $10(7.87)$ \\
\hline Treatment-emergent infections & $31(51.7)$ & $15(39.5)$ & $12(41.4)$ & $58(45.7)$ \\
\hline Treatment-emergent infections leading to withdrawal & $1(1.7)$ & 0 & $1(3.4)$ & $2(1.6)$ \\
\hline \multicolumn{5}{|l|}{ Treatment-emergent infections $\geq 5 \%$ subjects } \\
\hline Upper respiratory tract infection & $9(15.0)$ & $4(10.5)$ & $5(17.2)$ & $18(14.2)$ \\
\hline Pharyngitis & $9(15.0)$ & $4(10.5)$ & $2(6.9)$ & $15(11.8)$ \\
\hline Rhinitis & $4(6.7)$ & $2(5.3)$ & $2(6.9)$ & $8(6.3)$ \\
\hline Gastroenteritis & $3(5.0)$ & $1(2.6)$ & $1(3.4)$ & $5(3.9)$ \\
\hline Bronchitis & $1(1.7)$ & $3(7.9)$ & 0 & $4(3.1)$ \\
\hline Sinusitis & $3(5.0)$ & 0 & 0 & $3(2.4)$ \\
\hline Treatment-emergent SAEs* & 0 & $1(2.6)$ & 0 & $1(0.8)$ \\
\hline Serious treatment-emergent infections & $2(3.3)$ & 0 & $1(3.4)$ & $3(2.4)$ \\
\hline Infections considered preventable by vaccination in subjects not previously vaccinated & $1(1.7)$ & $1(2.6)$ & 0 & $2(1.6)$ \\
\hline Medically important infections & $2(3.3)$ & 0 & $1(3.4)$ & $3(2.4)$ \\
\hline Opportunistic infections & 0 & $1(2.6)$ & 0 & $1(0.8)$ \\
\hline
\end{tabular}

subjects with ERA with placebo-treated subjects from a jo-SpA study also yielded a similar outcome even if we acknowledge that the Mexican population enrolled by Burgos-Vargas et al might represent a more severe group of patients. ${ }^{30} \mathrm{~A}$ further comparison of JIA ACR 30 results from this study to the openlabel period from the first ETN study in subjects with polyarticular-course JRA showed similar proportions of subjects responding at 12 weeks. ${ }^{17}$ The percentages of subjects achieving the JIA ACR 50 and 70 endpoints were relatively higher in this study versus the original ETN study $(64 \%$ and $36 \%$, respectively) in which subjects were given ETN $0.4 \mathrm{mg} / \mathrm{kg}$ twice weekly but no concomitant DMARDs. Similar to other studies with TNFi agents, it is possible that the concomitant administration of DMARDs (mainly MTX), and the open-label design of our study may have resulted in more favourable outcomes.

Although this is the first study to prospectively investigate the effect of ETN specifically in eoJIA, ERA and PsA patients, previous studies have included such subjects within their patient population. ${ }^{23-2637}$ A prospective observational study of TNFi from the Dutch Arthritis and Biologicals in Children Registry observed similar proportions of subjects with ERA achieving JIA ACR 30 as observed in our study. ${ }^{23}$ The majority of these subjects $(n=20 / 22)$ were treated with ETN and concomitant DMARD. After 3 months, $86 \%$ of subjects achieved JIA ACR 30 and $73 \%$ achieved JIA ACR 70. One-third achieved inactive disease status (using the 2004 inactive disease criteria) ${ }^{38}$ which was slightly higher than those observed in our study. Similar results for the attainment of inactive disease status were obtained in the German Registry. ${ }^{39}$ By contrast, another retrospective study at an academic centre showed paediatric subjects with ERA receiving TNFi treatment were less likely to achieve inactive disease after 1 year than other JIA categories. ${ }^{20}$ In our study, the rate of inactive disease was similar in the three categories. A long-term observational analysis of subjects with PsA ( $n=17 / 18$ on ETN) from the Dutch Registry found similar results to those shown here for the joint symptoms ${ }^{37}$ with $83 \%$ of subjects achieving JIA ACR 30 after 3 months. Interestingly, the skin symptoms of subjects with PsA and psoriasis in the Dutch Registry did not respond well to treatment in contrast with the observed improvements shown in BSA and PGA of psoriasis in our study.

The efficacy of ETN in the eoJIA group in this study is also comparable with that observed in subjects with eoJIA treated with adalimumab, infliximab, or abatacept. ${ }^{11-13}$ 
ETN was well tolerated in this paediatric population for up to 12 weeks. Three serious infections were reported: one case each of gastroenteritis, bronchopneumonia and pyelocystitis. One case of herpes zoster was also reported. No cases of malignancy, autoimmune disorders, demyelinating disorders, infections considered preventable by vaccination in subjects previously vaccinated, or deaths were reported. However, the number of patient-years accrued with ETN in this study is not sufficient to draw any firm safety conclusions, while Part II of the study, which aimed to evaluate long-term safety, is still ongoing. The immunogenicity profile of ETN was favourable and consistent with studies in other paediatric and adult populations. ${ }^{19}$

The study was limited methodologically by the open-label design and use of historical data as the comparator instead of a placebo-control group and the lack of imaging especially for the ERA group. Additionally, subjects used different and varying concomitant therapies (DMARDs, glucocorticosteroids and NSAIDs) that may have had an effect on the efficacy responses. Another limitation was the lower age limit for inclusion in the PsA and ERA group which was set to 12 years; future studies should look at efficacy and safety profiles in lower age groups in PsA and ERA.

In conclusion, ETN $0.8 \mathrm{mg} / \mathrm{kg}$ once weekly treatment for 12 weeks was effective and well tolerated in children with eoJIA, ERA and PsA. ETN was not associated with unexpected safety findings reported in this paediatric population. The results of Part 2 of the 96 weeks of the CLIPPER study will provide further insight regarding the effects of ETN in these specific JIA categories.

\author{
Author affiliations \\ 'Department of Pediatrics, Asklepios Clinic, Sankt Augustin, Germany \\ ${ }^{2}$ Department of Rheumatology, Hospital General de Mexico, Mexico City, Mexico \\ ${ }^{3}$ Unit of Paediatric Rheumatology, Semmelweis University, Budapest, Hungary \\ ${ }^{4}$ Klinikum Eilbek, Hamburger Zentrum fuer Kinder und Jugendrheumatologie, \\ Hamburg, Germany \\ ${ }^{5}$ Faculty of Medicine, Clinic of Pediatrics, Clinical Center, University of Nis, Nis, \\ Serbia \\ ${ }^{6}$ Pediatric Department Hospital, State Pediatric Medical Academy, Saint-Petersburg, \\ Russian Federation \\ ${ }^{7}$ Department of Pediatric Nephrology and Urology, University Hospital Ghent, Ghent, \\ Belgium \\ ${ }^{8}$ Centre of Pediatrics, Vilnius University, Vilnius, Lithuania \\ ${ }^{9}$ Department of Pediatric Rheumatology, Belgrade Institute of Rheumatology, \\ Belgrade, Serbia \\ ${ }^{10}$ Department of Pediatrics, Riga Stradins University, Riga, Latvia \\ ${ }^{11}$ Wojewódzki Szpital Dziecięcy, Oddział Pediatrii Kardiologii i Reumatologii, \\ Bydgoszcz, Poland, Wojewódzki \\ ${ }^{12}$ Wojewódzki Specjalistyczny Szpital Dziecięcy sw. Ludwika ODS Reumatologia \\ Krakow, Poland \\ ${ }^{13}$ Unité de Rhumatologie Pédiatrique, Hôpital Necker-Enfants Malades, Paris, France \\ ${ }^{14}$ Department of Pediatric Rheumatology, University Children Hospital Gailezers, \\ Riga, Latvia \\ ${ }^{15}$ Clinica Pediatrica-Centro di Ricerca Clinica Fondazione dell'Universita' degli Studi \\ Gabriele D'Annunzio Via Colle dell'Ara, Chieti, Italy \\ ${ }^{16} 1$ st Medical Faculty, Charles University in Prague, General University Hospital in \\ Prague, Prague, Czech Republic \\ ${ }^{17}$ Hopital Cochin Service de Rhumatologie A Pavillon Hardy B, Paris, France \\ ${ }^{18}$ Department Pediatric Rheumatology, Universitair Ziekenhuis Utrecht Universitair \\ Ziekenhuis Utrecht Lundlaan 6 Utrecht, Utrecht, The Netherlands \\ ${ }^{19}$ Pfizer Inc, Collegeville, Pennsylvania, USA \\ ${ }^{20}$ Pediatria II, Reumatologia, Istituto G. Gaslini, Genoa, Italy \\ ${ }^{21}$ Dipartimento di Pediatria, Università di Genova, Genoa, Italy
}

Acknowledgements We wish to thank all additional members of PRINTO network who participated as investigators in the study, and whose enthusiastic effort made this work possible: (Australia) Jonathan Akikusa, MD, Jeffrey Chaitow, MD; (Belgium) Bernard Lauwerys, MD, Carine Wouters, MD; (Colombia) Juan Jose Jaller Raad, MD, William Jose Otero Escalante, MD, Patricia Julieta Velez, MD; (Czech Republic) Katerina Jarosova, MD, Marie Macku, MD; (France) Pierre Quartier, MD, Brigitte Bader-Meunier, MD; (Germany) Hans-Iko Huppertz, MD, Ralf Trauzeddel, MD; (Norway) Berit Flato, MD; (Poland) Bogna Dobrzyniecka, MD, Lidia
Rutkowska Sak, MD; (Russia) Evgeny Nasonov, MD; (Slovakia) Elena Koskova, MD; (Slovenia) Tadej Avcin, MD; (Spain) Inmaculada Calvo Penades, MD, Maria Luz Gamir, MD, Jordi Anton Lopez, MD.

Contributors Paper outline and major drafting and revisions were agreed between GH, RB-V, AM, NR and Pfizer. The first and subsequent drafts were critically reviewed by all coauthors. Medical writing assistance was provided by Kim Brown of UBC Scientific Solutions and was funded by Pfizer Inc. We confirm that all the named coauthors have participated in the conception and design, or analysis and interpretation of data, drafting the article or revising it critically for important intellectual content and final approval of the version to be published.

Funding This study was sponsored by Wyeth which was acquired by Pfizer Inc in October 2009.

Competing interests $\mathrm{GH}$ : has received grant/research support from: Abbott and Pfizer. RB-V: has received grant/research support from Abbott; has been a consultant for Abbott, BMS, Janssen, Pfizer, Roche; participated in Speakers Bureau for Abbott, BMS, Janssen, MSD, Pfizer, Roche. JV received speaker's bureaus from: Roche, Abbott, TEVA, and has been consultant for TEVA. VP has received grant/ research support from Janssen and Pfizer. DA, CZ, JW, DW and BV are all employees of Pfizer Inc. AM received speaker's bureaus from: Abbott, AstraZeneca, Boehringer, Brystol-Myers and Squibb, GSK, Novartis. NR received speaker's bureaus from: Abbott, AstraZeneca, Boehringer, Brystol-Myers and Squibb, Centocor, Novartis, Pfizer/Wyeth, Roche. The Gaslini Hospital, (Genoa, Italy), which is the public hospital where AM and NR work as full-time employees, has received contributions to support the Paediatric Rheumatology INternational Trials Organisation (PRINTO, http://www.printo.it) research activities from: Abbott, Bristol-Myers and Squibb, Centocor, Francesco Angelini, Italfarmaco, Novartis, Pfizer/Wyeth, Roche, Schwarz Biosciences, Xoma.

\section{Patient consent Obtained.}

Ethics approval The protocol was reviewed and approved by independent ethics committees/institutional review board at 38 centres in 19 countries included in the Paediatric Rheumatology International Trials Organisation (PRINTO).

Provenance and peer review Not commissioned; externally peer reviewed.

Open Access This is an Open Access article distributed in accordance with the Creative Commons Attribution Non Commercial (CC BY-NC 3.0) license, which permits others to distribute, remix, adapt, build upon this work non-commercially, and license their derivative works on different terms, provided the original work is properly cited and the use is non-commercial. See: http://creativecommons.org/ licenses/by-nc/3.0/

\section{REFERENCES}

1 Oen KG, Cheang M. Epidemiology of chronic arthritis in childhood. Semin Arthritis Rheum 1996;26:575-91.

2 Gare BA. Epidemiology. Baillière's Clin Rheumatol 1998:12:191-208.

3 Sacks JJ, Helmick CG, Luo YH, et al. Prevalence of and annual ambulatory health care visits for pediatric arthritis and other rheumatologic conditions in the United States in 2001-2004. Arthritis Rheum 2007;57:1439-45.

4 Ravelli A, Martini A. Juvenile idiopathic arthritis. Lancet 2007;369:767-78.

5 Petty RE, Southwood TR, Manners P, et al. International League of Associations for Rheumatology classification of juvenile idiopathic arthritis: second revision, Edmonton, 2001. J Rheumatol 2004;31:390-2.

6 Prakken B, Albani S, Martini A. Juvenile idiopathic arthritis. Lancet 2011;377:2138-49.

7 Hashkes PJ, Laxer RM. Medical treatment of juvenile idiopathic arthritis. JAMA 2005;294:1671-84.

8 Thornton J, Beresford MW, Clayton P. Improving the evidence base for treatment of juvenile idiopathic arthritis: the challenge and opportunity facing the MCRN/ARC Paediatric Rheumatology Clinical Studies Group. Rheumatology (Oxford) 2008:47:563-6.

9 van Rossum MA, Fiselier TJ, Franssen MJ, et al. Sulfasalazine in the treatment of juvenile chronic arthritis: a randomized, double-blind, placebo-controlled, multicenter study. Dutch Juvenile Chronic Arthritis Study Group. Arthritis Rheum 1998;41:808-16.

10 Ruperto N, Murray KJ, Gerloni V, et al. A randomized trial of parenteral methotrexate comparing an intermediate dose with a higher dose in children with juvenile idiopathic arthritis who failed to respond to standard doses of methotrexate. Arthritis Rheum 2004;50:2191-201.

11 Ruperto N, Lovell DJ, Cuttica R, et al. A randomized, placebo-controlled trial of infliximab plus methotrexate for the treatment of polyarticular-course juvenile rheumatoid arthritis. Arthritis Rheum 2007;56:3096-106.

12 Lovell DJ, Ruperto N, Goodman S, et al. Adalimumab with or without methotrexate in juvenile rheumatoid arthritis. N Engl I Med 2008;359:810-20.

13 Ruperto N, Lovell DJ, Quartier $\mathrm{P}$, et al. Abatacept in children with juvenile idiopathic arthritis: a randomised, double-blind, placebo-controlled withdrawal trial. Lancet 2008:372:383-91. 
14 Beukelman T, Patkar NM, Saag KG, et al. 2011 American College of Rheumatology recommendations for the treatment of juvenile idiopathic arthritis: initiation and safety monitoring of therapeutic agents for the treatment of arthritis and systemic features. Arthritis Care Res (Hoboken) 2011;63:465-82.

15 Ruperto N, Giannini EH, Pistorio A, et al. Is it time to move to active comparator trials in juvenile idiopathic arthritis?: a review of current study designs. Arthritis Rheum 2010;62:3131-9.

16 Lovell DJ, Reiff A, llowite NT, et al. Safety and efficacy of up to eight years of continuous etanercept therapy in patients with juvenile rheumatoid arthritis. Arthritis Rheum 2008:58:1496-504.

17 Lovell DJ, Giannini EH, Reiff A, et al. Etanercept in children with polyarticular juvenile rheumatoid arthritis. Pediatric Rheumatology Collaborative Study Group. N Engl J Med 2000;342:763-9.

18 US Food and Drug Administration. Medication guide Enbrel@ (etanercept). 2010; http:/ www.fda.gov/downloads/Drugs/DrugSafety/ucm088590.pdf (accessed 31 Aug 2012).

19 European Medicines Agency. Enbrel: summary of product characteristics. 2012; http:/l www.ema.europa.eu/docs/en_GB/document_library/EPAR_-_Product_Information/ human/000262NC500027361.pdf (accessed 13 Sep 2012).

20 Donnithorne KJ, Cron RQ, Beukelman T. Attainment of inactive disease status following initiation of TNF-alpha inhibitor therapy for juvenile idiopathic arthritis: enthesitis-related arthritis predicts persistent active disease. J Rheumatol 2011;38:2675-81.

21 Sulpice M, Deslandre CJ, Quartier P. Efficacy and safety of TNFalpha antagonist therapy in patients with juvenile spondyloarthropathies. Joint Bone Spine 2009:76:24-7.

22 Henrickson $M$, Reiff A. Prolonged efficacy of etanercept in refractory enthesitis-related arthritis. J Rheumatol 2004:31:2055-61.

23 Otten $\mathrm{MH}$, Prince $\mathrm{FH}$, Twilt $\mathrm{M}$, et al. Tumor necrosis factor-blocking agents for children with enthesitis-related arthritis-data from the dutch arthritis and biologicals in children register, 1999-2010. J Rheumatol 2011;38:2258-63.

24 Prince $\mathrm{FH}$, Twilt $\mathrm{M}$, ten Cate $\mathrm{R}$, et al. Long-term follow-up on effectiveness and safety of etanercept in juvenile idiopathic arthritis: the Dutch national register. Ann Rheum Dis 2009;68:635-41.

25 Horneff G, De Bock F, Foeldvari I, et al. Safety and efficacy of combination of etanercept and methotrexate compared to treatment with etanercept only in patients with juvenile idiopathic arthritis (JIA): preliminary data from the German JIA Registry. Ann Rheum Dis 2009;68:519-25.
26 Tse SM, Burgos-Vargas R, Laxer RM. Anti-tumor necrosis factor alpha blockade in the treatment of juvenile spondylarthropathy. Arthritis Rheum 2005;52:2103-8.

27 Ruperto N, Martini A. Networking in paediatrics: the example of the Paediatric Rheumatology International Trials Organisation (PRINTO). Arch Dis Child 2011;96:596-601.

28 Giannini EH, Ruperto N, Ravelli A, et al. Preliminary definition of improvement in juvenile arthritis. Arthritis Rheum 1997;40:1202-9.

29 Ruperto N, Pistorio A, Martini A, et al. A meta-analysis to estimate the "real" placebo effect in juvenile rheumatoid arthritis (JRA) trials. Arthritis Rheum 2003;48:S90.

30 Burgos-Vargas R, Casasola J. A twelve-week, randomized, double-blind, placebo-controlled trial to determine the effiacy and safety of infliximab in juvenile-onset spondyloarthropathies (JO-SPA). Ann Rheum Dis 2008;67(Suppl II):69.

31 Wallace CA, Giannini EH, Huang B, et al. American College of Rheumatology provisional criteria for defining clinical inactive disease in select categories of juvenile idiopathic arthritis. Arthritis Care Res (Hoboken) 2011;63:929-36.

32 Singh G, Athreya BH, Fries JF, et al. Measurement of health status in children with juvenile rheumatoid arthritis. Arthritis Rheum 1994;37:1761-9.

33 Ruperto N, Martini A. for the Paediatric Rheumatology International Trials Organisation (PRINTO). Quality of life in juvenile idiopathic arthritis patients compared to healthy children. Clin Exp Rheumatol 2001;19(Suppl 23):S1-172.

34 Ruperto N, Ravelli A, Pistorio A, et al. Cross-cultural adaptation and psychometric evaluation of the Childhood Health Assessment Questionnaire (CHAQ) and the Child Health Questionnaire (CHQ) in 32 countries. Review of the general methodology. Clin Exp Rheumatol 2001;19(Suppl 23):S1-9.

35 Garrett S, Jenkinson T, Kennedy LG, et al. A new approach to defining disease status in ankylosing spondylitis: the Bath Ankylosing Spondylitis Disease Activity Index. J Rheumatol 1994;21:2286-91.

36 Sieper J, Rudwaleit M, Baraliakos X, et al. The Assessment of SpondyloArthritis international Society (ASAS) handbook: a guide to assess spondyloarthritis. Ann Rheum Dis 2009;68(Suppl 2):ii1-44.

37 Otten MH, Prince FH, Ten Cate R, et al. Tumour necrosis factor (TNF)-blocking agents in juvenile psoriatic arthritis: are they effective? Ann Rheum Dis 2011;70:337-40.

38 Wallace CA, Ruperto N, Giannini E. Preliminary criteria for clinical remission for select categories of juvenile idiopathic arthritis. J Rheumatol 2004;31:2290-4.

39 Papsdorf V, Horneff G. Complete control of disease activity and remission induced by treatment with etanercept in juvenile idiopathic arthritis. Rheumatology (Oxford) 2011;50:214-21 